\title{
Interpersonal Communication that Inspires in EFL Teaching
}

\author{
Muhammad Amin Rasyid \\ muhammadaminrasyid_unm@yahoo.com \\ State University of Makassar, Indonesia
}

\begin{abstract}
This study attempted to reveal the perception of EFL students on the lecturer verbal and nonverbal interpersonal communication that they experience and expect to foster their positive attitudes and nurture their motivation in learning English at State University of Makassar, Indonesia. The respondents consisted of 152 fifth semester students of undergraduate program, majoring in English Education, attending TEFL course in 2013/2014 academic year. The study was guided by the researchers' teaching belief stating that teaching is communicating and inspiring virtues in the forms of knowledge, skills and attitudes. The instruments used were (a) The 14 lecturer verbal interpersonal communication measure (VICM) and (b) the 14 lecturer non-verbal interpersonal communication measure (NVICM) developed by the researcher. The data analysis showed that four of the 14 VICM were not inspiring, namely telling students his personal experience, responding students' reasons for being late, asking students to tell their most impressive learning English experience, and allowing students to call their lecturers by their first name; and three of the 14 NVICM were not inspiring, namely moving around the class when teaching, touching (shaking hands), coming closer to students when lecturing.
\end{abstract}

Key concepts: perception, inspiring, interpersonal, communication,

\section{INTRODUCTION}

Interpersonal communication is at the heart of classroom processes in EFL teaching. It is the EFL teacher/lecturer's central task for communicating messages in the forms of knowledge, skills and attitudes. To execute this very important role, an EFL teacher/lecturer should become a competent and effective communicator which exhibits the way he communicates appropriately and succinctly what to say, to whom to say it, how to say it, and where and when to say it. Developing such good interpersonal communication skills in the classroom requires good awareness of how he should appear to his students. This includes not only his verbal message delivery but also his nonverbal ones which create candid interpersonal communication that prevents communication barriers in classroom interaction. 
Students' misperceptions are mainly caused by poor interpersonal communication that exists among teacher - students, and students- students. On the other hands, better interpersonal communication will to a larger extent become the panacea of misperception.

\section{PURPOSE AND RESEARCH QUESTIONS}

The purpose of this study was to reveal the perception of EFL students on the interpersonal communication that they experience and inspire them to foster their positive attitudes and nurture their motivation in learning English at State University of Makassar, Indonesia. In line with the purpose of the study, the following research questions were posed.

1. What Interpersonal Verbal Communication do the fifth semester students of Undergraduate Program, majoring in English Education, attending TEFL course in 2013/2014 academic year perceive and rate to foster their positive attitudes and nurture their motivation in learning English?

2. What Interpersonal Non-Verbal Communication do the fifth semester students of Undergraduate Program, majoring in English Education, attending TEFL course in 2013/2014 academic year perceive and rate to foster their positive attitudes and nurture their motivation in learning English?

\section{LITERATURE REVIEW}

In order to have the same perception of the key terms used in this writing, the following brief explanations are given.

\section{a. Interpersonal Communication is defined}

Interpersonal Communication has been defined by communication experts as cited in the following.

Brooks and Heath (1993:7) defined interpersonal communication as "the process by which information, meanings and feelings are shared by persons through the exchange of verbal and nonverbal messages."

Wood (2010:17) stated that the best way to define interpersonal communication is "by focusing on what happens between people, not where they are or how many are present. ... that interpersonal communication is a distinct type of interaction between people."

Solomon \& Theiss (2013:5) stated that interpersonal communication "refers more specifically to communication that occurs between people and creates a personal bond between them." 
DeVito (2013:5) defined Interpersonal communication as the verbal and nonverbal interaction between two (or sometimes more than two) interdependent people. It is the communication the communication that takes place between people who are in some way "connected."

McCormack (2010:13) defined interpersonal communication as "a dynamic form of communication between two (or more) people in which the messages exchanged significantly influence their thoughts, emotions, behaviors, and relationships."

For practical implication in classroom context, interpersonal communication refers, in the writer's point of view, more specifically to communication that occurs among teachers/lecturers - students, and students-students which allows them to communicate both verbally and nonverbally in an effort to generate shared meanings and accomplish academic and social goals which creates a personal bond among them in terms of socially and psychologically perceived appropriate distance. However, not all cultures respond in the same way to verbal and nonverbal messages. In classroom context, like in other social contexts, not all students respond in the same way to lecturers' verbal and nonverbal messages.

\section{b. Verbal Message}

McCormack, (2010:182) defined verbal communication as "the exchange of spoken language with others during interaction." Verbal messages are those sent with words which may consist of both oral and written words.

\section{c. Non-verbal Message}

Patterson $(1983,1995)$ defined nonverbal communication as "the intentional or unintentional transmission of meaning through an individual's nonspoken physical and behavioral cues." Nonverbal messages are communicated through a variety of channels and their meanings will be greatly influenced by culture.

As far as the writers' teaching experiences in Indonesian university context, lecturers communicate in two modes of interpersonal communication, namely (a) Verbal Interpersonal Communication (VIC) which refers to stylistic verbal expressions (explicit messages) in delivering messages of knowledge, skills and attitudes to students (such as saying greeting when entering the class, praying before starting and ending the class, taking the register, giving advice to motivate students to study, calling on students by name when talking to them, and giving feedback to students), and (b) Nonverbal Interpersonal Communication (NVIC) which refers to implicit messages which are mediated by lecturers' actions such as eye gaze, facial expressions, gestures, body positioning, physical proximity, personal touch, and body movement. 


\section{d. The Concept of Inspiring is defined}

In view of the writer, the word inspiring in Bugis-Makassar culture comprises the meanings of stimulating, motivating, directing and encouraging people to think positively and to feel confidence to pursue in activities that have far- reaching positive effects. Based on this, inspiring teachers are those who have the ability to stimulate, motivate, direct and encourage students to think positively and to feel confidence to pursue in activities inside and outside classroom contexts that have far-reaching positive effects.

The Importance of Integrating Verbal and Nonverbal Messages in Teaching

It terms of teaching, it is advisable to put Interpersonal Communication as a whole and not to break it apart into verbal and nonverbal communication. It was reported that coupling both verbal and nonverbal constructs, appeared to increase student liking for instructors, decrease student apprehension, and increase overall student liking for the course and subject matter (Butland \& Beebe, 1992; Rodriguez, Plax, \& Kearney, 1996; and Plax et al.,1987). Both teacher nonverbal and verbal behaviors have shown to have a positive influence on students' affective (Baker, 2004; Gorham \& Christophel, 1990) and cognitive learning (Christophel, 1990). For lecturers, using verbal and nonverbal interpersonal communication that they are comfortable with and culturally accepted is the best choice.

\section{METHOD}

\section{a. Population and Sample}

The population consisted of 152 fifth semester students of undergraduate program (5 parallel classes) attending TEFL course in 2013/2014 academic year. The study employed census system taking all the members of the population as the research respondents.

\section{b. Instrumentation}

The instrument used consisted of 14 Item of Verbal Interpersonal Communication Measure (VICM), and 14 Item of Nonverbal Interpersonal Communication Measure (NVICM) with 1 (the least inspiring) to 5 (the most inspiring) range, that the writer developed, guided by the previously given concepts of VIC and NVIC. The measurement was in Indonesian version. 


\section{The Verbal Interpersonal Communication Measure (VICM)}

1. Saying Greeting when entering the class

2. Praying before starting and ending the class

3. Taking the register

4. Giving advice to motivate students to study

5. Calling on students by name when talking to them

6. Responding to students' reasons for being late

7. Giving feedback to students

8. Asking students to tell their most impressive learning English experience

9. Inserting humor in teaching

10. Telling students his personal experience

11. Allowing students to have individual and group consultation

12. Allowing students to call him by his first name

13. Asking students how they feel about their lessons and assignments given

14. Using terms like "we" and "us" to refer to the class

\section{The Nonverbal Interpersonal Communication Measure (NVICM)}

1. Starting and ending the lesson on time

2. Being enthusiastic in teaching

3. Looking at the class while teaching

4. Using gestures while talking to the class

5. Using vocal variety (non-monotone) when talking to the class

6. Smiling at the class while talking

7. Dressing neatly

8. Having a relaxed body posture while talking to the class

9. Having eye contact when calling on a student's name

10. Nodding along students' responses

11. Coming closer to students when lecturing

12. Walking from back to the front and side-to-side between rows when teaching (moving around the class when teaching)

13. Looking very little at board or notes while talking to the class

14. Shaking hands with students

The data were collected following the steps below.

1. Each class was divided into groups of $4-5$ students.

2. Each group discussed the 14 VICM items first then the 14 NVICM items to reach a group consensus.

3. The group consensuses were tabulated and paneled to see in what items each group was different from other groups in their scoring. 
4. An item scored differently having rating discrepancy with two intervals (for example $3-5$ or $2-4$ ) by the groups required the groups to give their arguments.

5. The consensus was achieved if the groups have agreed to the same score or two scores with only one interval rating discrepancy.

\section{Score Rate Used}

$$
\begin{aligned}
& 4.6-5.0 \text { most Inspiring } \\
& 4.0-4.5 \text { more Inspiring } \\
& 3.6-3.9 \text { Inspiring } \\
& 3.0-3.5 \text { less Inspiring } \\
& <3 \text { least Inspiring }
\end{aligned}
$$

For the VICM, the results of the study showed the following:

a. Six (6) VICM which were perceived and rated to be the most inspiring

b. Two (2) VICM which were perceived and rated to be the more inspiring

c. Two (2) VICM which were perceived and rated to be inspiring

d. Two (2) VICM were perceived and rated to be less inspiring, and

e. Two (2) VICM which were perceived and rated to be the least inspiring ones, in regard to inspiring the cultivation of positive attitudes and motivation that pursue to high interest in learning.

The VICM which carry positive values are the most inspiring, the more inspiring, and the inspiring ones, were perceived and rated to have powerful effect of stimulating, encouraging, supporting, directing the students to foster their positive attitudes and nurture their motivation to be more active in learning activities. On the other hand, the VICM which carry negative values are the least and the less inspiring ones were not perceived and rated to have powerful effect of leading students to have positive attitudes and high motivation in learning.

\section{Findings And Discussion}

\section{The Six most inspiring VIC}

\section{Praying before starting and ending the class}

This means teachers/ lecturers should lead the class to seek for guidance, inspiration, help and direction from Allah the Most Beneficent and the Entirely Merciful, The Knower, the Owner of all knowledge, followed by total submission to Him to be successful in studying. 


\section{Taking the register}

This means that teachers/ lecturers should check the students' attendance.

This shows that lecturers have caring attitudes toward students.

\section{Calling on students by name when talking to them}

This means that teachers/ lecturers should know well their students' names as each student has his/her own name, and his/her name is something very valuable in his/her life.

\section{Giving advice to motivate students to study}

This means that teachers/ lecturers should guide their students to strive for excellence.

\section{Giving feedback to students}

This means that teachers/ lecturers should tell their students' progress, what they have done correctly and what they should improve and make more efforts for better achievement.

6. Saying greeting when entering the class

This means that teachers/ lecturers welcome their students to the lesson. This will make the students feel important in the eyes of the lecturers.

\section{The two more inspiring VIC}

\section{Inserting humor in teaching}

This means that teachers/lecturers should create free- stress situations that make students feel comfortable.

\section{Allowing students to have individual and group consultation}

This means that teachers/lecturers are willing to give further guidance to students either individually or in groups.

\section{The two inspiring VIC}

1. Using terms like "we" and "us" to refer to the class

This means that teachers/ lecturers should build up the feeling of togetherness, being in oneness that cultivates sentiments of inclusiveness.

2. Asking students how they feel about their lessons and assignments given This means that teachers/ lecturers should get feedback from the students, especially in terms of difficulties the students encounter. 
40| ELT Worldwide Vol. 2 No. 2 October 2015

\section{The two less inspiring VIC}

\section{Telling students his personal experience}

This means that teachers/ lecturers should focus their explanation on the material they are teaching, and avoid taking away the students' attention from the teaching material.

2. Responding students' reasons for being late

This means that teachers/lecturers and students should make regulations that allow the late comers do not interrupt the class.

\section{The two least inspiring VIC}

1.Asking students to tell their most impressive learning English experience The students argued that this could be done in the first meeting only.

2. Allowing students to call him by his first name

Addressing teachers/lecturers by their first name is considered to be very impolite. The local culture ( South Sulawesi) does not give room for such a behavior. Students should pay respect to their teachers/lecturers and address them by honorific address.

For the NVICM, the results of the study showed the following:

1. Four (4) NVICM which were perceived to be the most inspiring

2. Seven (7) NVICM which were perceived to be the more inspiring

3. Three (3) NVICM which were perceived to be the least inspiring ones, in regard to stimulating the cultivation of positive attitudes and motivation pursuing to high interest in learning.

Likewise the VICM, the NVICM which carry positive values are the most inspiring, and the more inspiring ones were interpreted to have powerful effect of stimulating, encouraging, supporting, directing the students to foster their positive attitudes and nurture their motivation to be more active in learning activities. On the other hand, the NVICM which carry negative values are the least favorable ones were not interpreted to have powerful effect of leading students to have positive attitudes and high motivation in learning.

\section{The four most inspiring NVICM}

\section{Being enthusiastic in teaching}

Teachers/lecturers should put enthusiasm in the frame of their teaching which is constructed in well-established readiness for teaching. This will pour spirit to the students' mind to be more enthusiastic as well. 


\section{Starting and ending the lesson on time}

Beginning and ending the class on time is the prerequisite of effective classroom management. It will no do any harm to others. The planned classroom activities will most likely run accordingly. On the other hand, coming late to class will most of the time cause many problems, such as the class activities will surely be in disorder as such amount of time is corrupted. Giving compensation for the corrupted time creates another problem, and so on.

\section{Dressing neatly}

Teachers/lecturers' physical appearance has a direct bearing on their students' perception. Therefore, they should dress neatly to have neat appearance in their professional activities. Appearing physically neat and clean will reflect their clear, modest, thoughtful and managerial mind, so that their presence in the classroom will highly be welcome, expected and respected by the students. Clothing signals a great amount of information about self, and that is why clothing does communication.

\section{Looking at the class while teaching}

Teachers/Lecturers looking at the class while teaching are perceived by the students as more confident, credible, and honest as eyes serve as the mirrors of the soul. It also means that the lecturers give their undivided attention to the class.

\section{The seven more inspiring NVICM}

1. Using vocal variety (non-monotone) when talking to the class

Teachers/Lecturers' moods and emotions are reflected in their tone of voice, and the students will pick up on non verbal clues and react accordingly. Therefore, it is important for lecturers to make use their voice as well as possible to build rapport. What they say and how they say it carry great influence on the way students react.

\section{Nodding along students' responses}

Nodding along students' responses creates the perception of engagement and agreements in the sense that the teachers/lecturers are paying attention to and agree with the students and to their ideas.

\section{Having a relaxed body posture while talking to the class}

Teachers/lecturers should appear natural and relaxed. When sitting, they should make sure that the small of their back is firmly supported in their chair to give them a well- supported posture; and when standing, their weight is well balanced on both feet so that their stance is strong. By this way, they can create a positive rapport and right impression to the students. 


\section{Smiling at the class while talking}

Warm and sincere smiles touch the inner heart, invite kindness and appeal friendliness and have the power to make ourselves feel better about ourselves and the world around us. In teaching, smiling face teachers/ lecturers are perceived by the students that they are happy and enjoying their teaching that will also make the students enjoy learning from them. A teacher/lecturer cannot expect his students to enjoy learning if he himself does not enjoy teaching.

\section{Having eye contact when calling on a student's name}

Appropriate eye contact will create bonds of acceptance and trust between teachers/lecturers and students. The students will feel that their teachers/ lecturers care them.

\section{Using gestures while talking to the class}

Gesturers communicate and help clarify the verbal expressions. Using appropriate gestures facilitate students' understanding.

\section{Looking very little at board or notes while talking to the class}

This means the teachers/ lecturers know well the materials they are teaching. They have good professional competence. Students like learning from lecturers who are professionally competent.

\section{The three least inspiring NVICM}

1.Walking from back to the front and side-to-side between rows when teaching (moving around the class when teaching)

This NVIC was rated by the students to distract their attention as lecturers do not look at the class as a whole.

\section{Shaking hands with students}

This NVIC was rated by the students to violate the Islamic teaching. (Most of the respondents are female Muslim students). Shaking hands with the opposite sex who are not the 'muhrim' (degree of consanguinity between a man and a woman that renders marriage impossible but gives them the right of association.) is 'haram' (unlawful).

\section{Coming closed to students when lecturing}

Coming closed to students when teaching was rated by the students to be a territory invasion. It was argued that teachers/lecturers should keep a distance which allows the students to feel secure, pleasant, and enjoyable. 


\section{CONCLUSION}

The results of the study showed that (1) the respondents' rating of Interpersonal Communication was much dictated by their faith (religion) and culture, (2) the statements of lecturer immediacy behaviors which are in the frame of their belief and culture were perceived to be inspiring and stimulating the cultivation of positive attitudes and motivation pursuing to high interest in learning, and those which lie outside were perceived to be less or least inspiring.

\section{SUGGESTION}

For lecturers, using verbal and nonverbal interpersonal communication that they are familiar and comfortable with and which lies within the frame of students' belief, favor and culture is the best choice.

\section{References}

Brooks, W. and Heath, R. (1993) Speech Communication. Dubuque, IA: W.C. Brown.

Butland, M. J., \& Beebe, S. A. (1992).Teacher immediacy and power in the classroom: The application of implicit communication theory. Paperpresented atthe Annual Meeting of theInternational Communication Association, Miami, FL.

Christophel, D.M., (1990). The relationships among teacher immediacy behaviors, student motivation, and learning. CommunicationEducation, 39, 323-340.

DeVito, Joseph A. (2013. The Interpersonal Communication Book Boston: Pearson Education, Inc.

Gorham, J., \& Christophel, D. M. (1990).The relationship of teachers' use of Humor in the classroom to immediacy and student learning. Communication Education,30, 46-62.

McCornack, Steven. (2010.) Reflect \& Relate: An Introduction to Interpersonal Communication. Second Edtion. Boston: Bedford/St. Martin's 
Patterson, M. L. (1983). Nonverbal behavior: A functional perspective. New York: Springer-Verlag.

Patterson, M. L. (1995). A parallel process model of nonverbal communication.Journal of Nonverbal Behavior, 19, 3-29.

Plax, T. G., Kearney, P., Mc Croskey, J.C., \& Richmond, V. P. (1987). 'Power in the classroom VI: Verbal control strategies, nonverbal immediacy and affective learning'. Communication Education, 35, 43-55.

Rodriguez, J. I., Plax, T. G., \& Kearney, P. (1996).Clarifying the relationship between teacher nonverbal immediacy and student cognitive learning: Affective learning a the central causal mediator.Communication Education, 45, 293-305.

Solomon, Denise and Jennifer. (2013.) Interpersonal Communication: Putting Theory into Practice. Abingdon: Taylor \& Francis.

Witt, P. L., Wheeless, L. R., \& Allen, M. (2004).A meta-analytical review of the relationship between teacher immediacy and student learning.CommunicationMonographs, 71(2), 184-207.

Wood, Julia T. (2010.) Interpersonal Communication: Everyday Encounters. Six Edition. Boston: Wadsworth, Cengage Learning 